\title{
The effect and mechanism of improved efficiency of physicochemical pro-release treatment for low grade phosphate rock
}

\author{
L. Huang, X.-y, Mao*, J. Wang, X. Chen, G.-h, Wang, Z.-w, Liao \\ College of Natural Resources and Environment, South China Agriculture University, Guangzhou, 510642, China * Corresponding \\ author:xymao@scau.edu.cn
}

\begin{abstract}
With the increasingly acute contradictions between shortage of bonanza phosphorus resources and phosphate fertilizer demands, to develop an efficient use technology for low-grade phosphate rocks (LGPR) was an inevitable choice. In this study, the physicochemical pro-release phosphate rock (PCPR) was prepared by adding modified lignin during the process of ultra-fine grinding LGPR. The relationship between phosphorus chemical composition of PCPR, molecular structure and fertilizer efficiency was explored by chemical analysis, spectral analysis and pot experiment. The results showed that after pro-release treatment of phosphate rock (PR), available phosphorus, reactive phosphorus and soluble phosphorus levels were significantly increased compared with PR. The available phosphorus content increased by $40 \%$, the reactive phosphorus content increased more than 3.5 times, and 6 consecutive extraction soluble phosphorus accumulation increased by 24 times. The structure of the PR showed the pro-release processing would significantly increase particle fineness and specific surface area of $\mathrm{PR}$, strengthen the characteristic absorption peak intensity of $\mathrm{PO}_{4}^{3-}, \mathrm{HPO}_{4}^{2-}$, replace the $\mathrm{Cl}-\mathrm{F}^{-}, \mathrm{Fe}^{2+}$ in the apatite and change the phase composition of PR. Pot experiment results showed corn biomass and phosphorus utilization processed by the PCPR were much higher than superphosphate (SP), diammonium phosphate(DAP), and significantly improve soil phosphorus content. The high soluble phosphorus and active phosphorus in PCPR providing the moderate continuous phosphorus supply intensity was the main reason for its high bioavailability. The combination of a static extraction and continuous extraction of reactive phosphorus and soluble phosphorus was an appropriate evaluation of physicochemical pro-release effect.
\end{abstract}

Keywords: Physicochemical pro-release treatment, phosphate rock, phosphorus composition, molecular structure, mechanism.

Abbreviations: PR (phosphate rock), LGPR (low grade phosphate rock), PCPR (physicochemical pro-release phosphate rock), UFPR (ultrafine phosphate rock), SP (superphosphate), DAP (diammonium phosphate). 


\section{Introduction}

Phosphate rock (PR) is an essential raw material for phosphorus fertilizer production, an important strategic non-renewable resources, is significant for the promotion of food production and sustainable agricultural development (Cordell et al., 2011; Schroder et al., 2011; Taheri et al., 2012). As the large number of phosphate fertilizer products were inputted in agricultural production, phosphate resources (especially high-grade phosphorus ore resources) crisis was increasingly obvious, becoming a worldly common challenge today (Van Vuuren et al., 2010; Dawson et al., 2011). Although China's total reserves of phosphate rock resources was rich, more than $80 \%$ was low-grade phosphate rock (LGPR), P2O5 content was less than $17 \%$ in the average ( $\mathrm{Lu}, 2004)$. Due to the high impurity content and difficult enrichment, the direct application of PR effect was not ideal as a fertilizer. Meanwhile, it was difficult to meet the needs of high-concentration phosphate fertilizer production (Liao et al., 2011). In 2010, Chinese phosphate fertilizer production reached 16.43 million tons $\left(\mathrm{P}_{2} \mathrm{O}_{5}\right)$, more than one third of total world phosphate fertilizer. Due to continuous demand for food with population growth, Chinese agricultural production will further increase the demand for phosphate fertilizer for a long period in the future. Phosphorus resource shortages will become a serious threat to China's food security. Hence, investigation and development of efficient use technology for LGPR resources to alleviate the crisis and to ensure food security was an inevitable choice.

Recently, the direct use technology of LGPR from microbial composting, ultra-fine grinding and phosphorus activation was increasingly taken seriously (Biswas et al., 2006; Sukhov et al., 2007; Walker et al., 2012). Such technology not only can significantly improve the effectiveness of $\mathrm{PR}$ and phosphorus agricultural value, but also did not require beneficiation of LGPR, which can effectively avoid the high costs and environmental risks beneficiation tailings brought out (He et al., 1999; Chien et al., 2011). However, microbial composting needed inoculate microbial strains and large amounts of organic waste, sulfur and other auxiliary materials, with length composting cycle (60-120days), and the production of fertilizer products was with low $\mathrm{pH}(\mathrm{pH}<3)$, which would cause further soil acidification (Osivand et al., 2009; Aria et al., 2010). The ultra-fine grinding technology process was simple, but the grinding efficiency was low. At the same time, the ultra-fine grinding technology generally required 60-90min with large energy consumption and high production costs (Minjigmaa et al., 2007). Phosphorus activator was a class of high surface activity and a large number of active groups of inorganic mineral or organic , not only can significantly promote the release of phosphorus, but also effectively reduce soil phosphorus fixation, improve utilization of phosphorus. Direct application of phosphorus activator in the activation of LGPR has become a new area of research focus (Pickering et al., 2002; Liao et al., 2011). Among known phosphorus activator, lignin and its modified products owned high surface activity and dispersion, not only could be as an efficient activation of phosphorus fertilizer applying in activator production, but also can be used as grinding aids for inorganic mineral ultrafine grinding process in order to improve the grinding efficiency. Therefore, the application phosphorus activator like lignin in ultrafine grinding process of PR would improve the efficiency of PR grinding while promoting activation of phosphorus, was expected to form energy-efficient technologies in the direct use of LGPR. Until now, the researches about application of lignin phosphorus activator and mechanical force synergistic activation of physicochemical phosphate rock (PCPR) were few and the synergic mechanism was rarely reported.

In this study, the synergistic effect of activation PR under the conditions of ultra-fine grinding was investigated using lignin sulfonate as phosphorus activator. The microstructures of ultra-fine phosphate rock (UFPR), PCPR as well as PR were analyzed to explore the intrinsically relationship between the changes in the microstructure of PR and phosphorus 
availability by virtue of the technologies such as the laser particle size analyzer, X-ray diffraction analysis, IR spectroscopy analysis and so on. Potted plant fertilizer test and phosphorus fertilizer morphological analysis revealed the mechanism of the high available phosphorus for PCPR. The technology would provide an idea for promotion of application and research in physicochemical pro-release technology of LGPR, and supply technical support and scientific basis for the efficient use of Chinese resources in LGPR to mitigate phosphate crisis.

\section{Materials and Methods}

\subsection{PCPR preparation}

PR1 produced from Yichun city of Hubei Province and PR2 produced in Liuyang city of Hunan Province,belong to the sedimentary phosphate rock and minerals (Table 1). Sodium lignosulfonate, total phosphorus $\left(\mathrm{P}_{2} \mathrm{O}_{5}\right)$ content $1.16 \mathrm{~g} / \mathrm{kg}$ and water $4.6 \%$, used as activator. Firstly, mixed $95 \%$ (w) phosphate rock with a particle size of 100 mesh and $5 \%(w)$ sodium lignosulfonate, added appropriate water, ground them in the bead mill (produced by Swiss Buhler Perl Mill ${ }^{\circledR}$ PML-H / V-type) for $15 \mathrm{~min}$ with zirconia beads as grinding media. Concentrated emulsions, dried at $60{ }^{\circ} \mathrm{C}$. Then the physicochemical pro-release phosphate rock (PCPR1, PCPR2) samples were obtained. The ultra-fine phosphate rock (UFPR1, UFPR2) samples were obtained without adding sodium lignosulfonate under the same conditions. Sample size was determined through the BT-9300S laser particle size distribution analysis system.

\subsection{Phosphorus release dynamic measurement}

Weighed $0.5000 \mathrm{~g}$ phosphorus samples in $50 \mathrm{~mL}$ centrifuge tube, added $50 \mathrm{~mL}$ of distilled water, shook at $(25 \pm 1){ }^{\circ} \mathrm{C}$ for $15 \mathrm{~min}$ (shaken speed at 200 $\mathrm{r} / \mathrm{min}$ ), centrifuged $10 \mathrm{~min}(4000 \mathrm{r} / \mathrm{min})$, and then filtered them with quantitative filter paper (without phosphate). The filtrate was transferred into 100 $\mathrm{mL}$ plastic bottle, added $50 \mathrm{~mL}$ of distilled water to the remaining sample residue. The process of shaking centrifugation and filtration was repeated 6 times according to the above method. The soluble phosphorus in filtrate was determined with $\mathrm{Mo}-\mathrm{Sb}$ colorimetric method (Lu et al., 2000).

Table 1. The grade and chemical components of phosphate rocks

\begin{tabular}{cccccccc}
\hline $\begin{array}{c}\text { Phosphate } \\
\text { rocks }\end{array}$ & $\begin{array}{c}\text { Total } \\
\text { phosphorus } \\
\left(\mathrm{P}_{2} \mathrm{O}_{5} \%\right)\end{array}$ & $\begin{array}{c}\text { Available } \\
\text { phosphorus } \\
\left(\mathrm{P}_{2} \mathrm{O}_{5} \%\right)\end{array}$ & $\mathrm{pH}$ & $\begin{array}{c}\mathrm{CaO} \\
(\%)\end{array}$ & $\begin{array}{c}\mathrm{Fe}_{2} \mathrm{O}_{3} \\
(\%)\end{array}$ & $\begin{array}{c}\mathrm{Al}_{2} \mathrm{O}_{3} \\
(\%)\end{array}$ & $\begin{array}{c}\mathrm{MgO} \\
(\%)\end{array}$ \\
\hline $\mathrm{PR} 1$ & 18.02 & 1.56 & 8.70 & 31.75 & 1.30 & 0.37 & 3.38 \\
$\mathrm{PR} 2$ & 23.16 & 4.47 & 8.63 & 35.62 & 2.02 & 1.00 & 1.07 \\
\hline
\end{tabular}

PR1, phosphate rock of Yicheng City; PR2, phosphate rock of Hunan Province. 


\subsection{Phosphorus forms analysis}

The available phosphorus before and after PR prorelease treatment was measured with $2 \%$ citric acid extraction - vanadium-molybdenum yellow colorimetry (Lu et al., 2000); the active phosphorus was extracted with $1 \mathrm{~mol} / \mathrm{L}$ acetic acid - sodium acetate $(\mathrm{pH}=4.7)$ and determined with vanadium molybdenum yellow colorimetry (Zheng et al., 1989).

\subsection{Structural analysis}

The phosphorus samples were ground and sieved to 200 meshes, and subjected to X-diffraction and infrared spectroscopy analysis. The X-ray diffraction pattern of PR and UFPR, PCPR were examined in Philips X'pert X-ray diffraction at $\mathrm{Cu}$ target $(0.54056 \mathrm{~nm})$, accelerating voltage $40 \mathrm{kV}$, filament current $30 \mathrm{~mA}$, step width $0.017 \mathrm{deg}, 2 \theta$ scanning speed of $0.5^{\circ} /$ min, scan range $3-70^{\circ}$. The phase composition of phosphorus samples were qualitatively analyzed with Jade 6.5 software and PDF card library.

For the Infrared Spectroscopy analysis (FTIR), mixed about $1 \mathrm{mg}$ phosphorus samples and $200 \mathrm{mg}$ pure spectrum level $\mathrm{KBr}$ powder in an agate mortar and tableted them. Then the infrared spectrum sample was obtained and examined in Perkin-Elmer1725X Nicolet infrared spectrometer (USA) at internal chamber vacuum $P=6 \mathrm{mbar}$, scans times 64 , scan range 400 $4000 \mathrm{~cm}^{-1}$, wavenumber accuracy $0.001 \mathrm{~cm}^{-1}$, the highest resolution $0.1 \mathrm{~cm}^{-1}$, the measurement error of about $\pm 1 \mathrm{~cm}^{-1}$.

\subsection{Pot experiment}

The test fertilizers were urea with nitrogen $46 \%$, potassium chloride with available potassium $\left(\mathrm{K}_{2} \mathrm{O}\right) 60 \%$, superphosphate (SP) with available phosphorus $\left(\mathrm{P}_{2} \mathrm{O}_{5}\right) 12 \%$, diammonium phosphate (DAP) AR, ordinary phosphate rocks (PR1, PR2), ultra-fine phosphate rocks (UFPR1, UFPR2) and physicochemical pro-release phosphate rocks (PCPR1, PCPR2). The soil was upland red soil developed from
Guangzhou Wushan granite with $18.21 \mathrm{~g}^{\bullet} \mathrm{kg}^{-1}$ organic matter, $5.40 \mathrm{pH}$. The contents of total amount of nitrogen, phosphorus $\left(\mathrm{P}_{2} \mathrm{O}_{5}\right)$, potassium $\left(\mathrm{K}_{2} \mathrm{O}\right)$ in soil were $0.27,0.37$ and $3.80{\mathrm{~g} \cdot \mathrm{kg}^{-1}}^{-1}$ and the contents of effective nitrogen, phosphorus $\left(\mathrm{P}_{2} \mathrm{O}_{5}\right)$, potassium $\left(\mathrm{K}_{2} \mathrm{O}\right)$ were $22.61,11.05$ and $35.47 \mathrm{mg} \mathrm{kg}^{-1}$, respectively. The corn seeds were waxy corn CAU 2008 provided by South China University of Agriculture, Guangzhou, China.

The test was set for 9 treatments with four replications. Mounted pot with $4 \mathrm{~kg}$ soil, each treatment was fertilized with same amount of nitrogen and potash. Nitrogen fertilizer was applied with $150 \mathrm{mg}$ of nitrogen per kg dry soil and the amount of urea per pot was $1.30 \mathrm{~g} ; 120 \mathrm{mg}$ potash $\left(\mathrm{K}_{2} \mathrm{O}\right)$ was applied per $\mathrm{kg}$ dry soil and pot potassium chloride dosage was 0.80 g; $100 \mathrm{mg}$ phosphate $\left(\mathrm{P}_{2} \mathrm{O}_{5}\right)$ was applied per kg dry soil, 0.74 g DAP was applied per pot, SP treatment dosage per pot was $3.33 \mathrm{~g}$, and the amount of other phosphate fertilizer treatments was the same with SP. All fertilizer was applied one time as basal fertilizer. The specific fertilization programs are shown in Table 2. Corns were seeded on the July 15, 2012. Four germinated corn seeds were sowed in one pot. After a week, 3 corn seedlings were planted in a pot. The corn was harvested on August 23 (period of growth $41 \mathrm{~d}$ ). The aboveground part and roots were harvested (rinse with water). After drying plant and weighting, the total phosphorus in the plant was analyzed. The soil samples were obtained after plants were harvested. The airdried soil was analyzed for phosphorus content. Plant total phosphorus analysis method adopted $\mathrm{H}_{2} \mathrm{SO}_{4}$ $\mathrm{H}_{2} \mathrm{O}_{2}$ digestion- Mo-Sb colorimetry, soil phosphorus analysis method adopted $0.025 \mathrm{~mol} \mathrm{~L}^{-1} \mathrm{HCl}-0.03 \mathrm{~mol}$ $\mathrm{L}^{-1} \mathrm{NH} 4 \mathrm{~F}$ (Lu et al., 2000).

\subsection{Statistical analysis}

The data obtained was subjected to analysis of variance(ANOVA). The mean values of four replicates were compared using the standard error of the mean and the Duncan test $(p=0.05)$. 
Table 2. Pot experiment on PCPRs different phosphorus fertilizers

\begin{tabular}{ccc}
\hline Treatment & Type of phosphate fertilizer & $\left(\mathrm{g} \mathrm{pot}^{-1}\right)$ \\
\hline CK & ---- & --- \\
SP & Superphosphate & 3.33 \\
DAP & Diammonium phosphate & 0.74 \\
PR1 & Phosphate rock of Yichen City & 3.33 \\
UFPR1 & Ultra-fine PR1 & 3.33 \\
PCPR1 & Physicochemical pro-release PR1 & 3.33 \\
PR2 & Phosphate rock of Hunan Province & 3.33 \\
UFPR2 & Ultra-fine PR2 & 3.33 \\
PCPR2 & Physicochemical pro-release PR2 & 3.33 \\
\hline
\end{tabular}

\section{Results}

\subsection{Ultrafine particle size distribution and apparent nature of PCPR}

The particle size of phosphate rock PR1, PR2 $(150 \mu \mathrm{m})$ was significantly reduced after the treatment of the ultrafine grinding and physicochemical pro-release, reaching micron level. In the ultra. fine grinding process, adding activator can further improve the grinding efficiency of PRs, significantly reduce particle size of phosphate powder and increase specific surface area. Compared with UFPR1, the medium particle size of PCPR 1 reduced by $77.93 \%$ and the specific surface area increased 1.10 times; compared with UFPR2, the medium particle size of PCPR 2 reduced by $90.63 \%$ and the specific surface area increased 1.31 times (Table 3 ).

Table 3. The particle size distribution of UFPRs and PCPRs

\begin{tabular}{cccc}
\hline Treatment & $\begin{array}{c}\text { Particle size } \\
(\mu \mathrm{m})\end{array}$ & $\begin{array}{c}\text { D90 } \\
(\mu \mathrm{m})\end{array}$ & $\begin{array}{c}\text { Specific surface area } \\
\mathrm{m}^{2} / \mathrm{g}\end{array}$ \\
\hline UFPR1 & 10.71 & 46.23 & 0.67 \\
PCPR1 & 2.36 & 8.74 & 1.41 \\
UFPR2 & 21.13 & 83.77 & 0.55 \\
PCPR2 & 1.98 & 8.44 & 1.27 \\
\hline
\end{tabular}

UFPR1 and UFPR2, ultra-fine phosphate rock; PCPR1 and PCPR2, physiochemical pro-release phosphate rock; D90, 90\% particle size range. 
3.2. The dynamic release characteristics and phosphorus forms analysis of PCPR

Seven different phosphate continuous water extraction results showed (Table 4), water soluble phosphorus from SP 1st extraction was high, but decayed very fast. The second extraction was only $5.76 \%$ of the 1 st. After the first three times, the amount of extraction will be less than the PCPR2, and the 6th extraction was only $0.66 \%$ of 1 st. PRs possessed low content of watersoluble phosphorus content, each extraction volume was at a low level. The soluble phosphorus in the UFPRs did not change significantly and the difference was not significant compared with the untreated PRs. Adding activator during ultra-fine grinding PRs could significantly increase the water-soluble phosphorus content in PCPRs, in which the cumulative total amount of water-soluble phosphorus in 6 times extraction of PCPR1 was 41.66 and 16.58 times of PR1 extraction and UFPR1 extraction, respectively. And the total amount of water-soluble phosphorus in
6 times extraction of PCPR 2 was 24.70 and 57.42 times of PR2 extraction and UFPR2 extraction, respectively. Compared with the SP, there was a small decline in the amount of water-soluble phosphorus for PCPR1 and PCPR2 continuous extraction, with sustainable and balanced release. (Table 5)

Ultrafine grinding or physicochemical pro-release treatments could significantly increase available phosphorus and active phosphorus in PR, in which physicochemical pro-release treatment promoted more obvious available phosphorus and active phosphorus in PR. Compared with PR1, the available phosphorus and active phosphorus in PCPR1 were increased by $61.82 \%$ and $391.54 \%$; compared with UFPR 1 , they were increased by $16.76 \%$ and $19.47 \%$. The available phosphorus and reactive phosphorus in PCPR2 were also increased by $42.18 \%$ and $350.36 \%$ as compared with the PR2, and increased by $10.15 \%$ and $42.69 \%$ as compared with the UFPR2.

Table 4. Comparison of phosphorus releasing dynamics between PRs and UFPRs, PCPRs $\left(\mathrm{P}_{2} \mathrm{O}_{5}\right)$

\begin{tabular}{ccccccc}
\hline $\begin{array}{c}\text { Phosphoric } \\
\text { fertilizer }\end{array}$ & $\begin{array}{c}\text { First } \\
\left(\mathrm{mg} \cdot \mathrm{kg}^{-1}\right)\end{array}$ & $\begin{array}{c}\text { Second } \\
\left(\mathrm{mg} \cdot \mathrm{kg}^{-1}\right)\end{array}$ & $\begin{array}{c}\text { Third } \\
\left(\mathrm{mg} \cdot \mathrm{kg}^{-1}\right)\end{array}$ & $\begin{array}{c}\text { Fourth } \\
\left(\mathrm{mg} \cdot \mathrm{kg}^{-1}\right)\end{array}$ & $\begin{array}{c}\text { Fifth } \\
\left(\mathrm{mg} \cdot \mathrm{kg}^{-1}\right)\end{array}$ & $\begin{array}{c}\text { Sixth } \\
\left(\mathrm{mg} \cdot \mathrm{kg}^{-1}\right)\end{array}$ \\
\hline SP & $89134.25 \pm 1191.55^{\mathrm{a}}$ & $5137.67 \pm 86.46^{\mathrm{a}}$ & $2013.89 \pm 40.31^{\mathrm{b}}$ & $1389.25 \pm 20.20^{\mathrm{b}}$ & $709.68 \pm 23.78^{\mathrm{b}}$ & $586.76 \pm 17.08^{\mathrm{c}}$ \\
PR1 & $22.05 \pm 0.94^{\mathrm{c}}$ & $25.39 \pm 3.77^{\mathrm{d}}$ & $23.61 \pm 1.90^{\mathrm{d}}$ & $15.82 \pm 1.57^{\mathrm{e}}$ & $25.06 \pm 0.48^{\mathrm{e}}$ & $24.95 \pm 1.27^{\mathrm{e}}$ \\
UFPR1 & $57.00 \pm 2.96^{\mathrm{c}}$ & $61.87 \pm 2.04^{\mathrm{d}}$ & $71.12 \pm 0.78^{\mathrm{d}}$ & $60.32 \pm 0.48^{\mathrm{de}}$ & $49.52 \pm 0.14^{\mathrm{e}}$ & $44.22 \pm 0.16^{\mathrm{e}}$ \\
PCPR1 & $1449.05 \pm 102.12^{\mathrm{c}}$ & $967.90 \pm 71.49^{\mathrm{c}}$ & $1029.25 \pm 0.61^{\mathrm{c}}$ & $743.82 \pm 43.56^{\mathrm{c}}$ & $665.72 \pm 0.32^{\mathrm{c}}$ & $847.10 \pm 14.87^{\mathrm{b}}$ \\
PR2 & $31.10 \pm 0.94^{\mathrm{c}}$ & $70.13 \pm 0.61^{\mathrm{d}}$ & $110.69 \pm 1.85^{\mathrm{d}}$ & $126.24 \pm 1.69^{\mathrm{d}}$ & $121.66 \pm 1.30^{\mathrm{d}}$ & $146.74 \pm 2.63^{\mathrm{d}}$ \\
UFPR2 & $30.50 \pm 1.02^{\mathrm{c}}$ & $24.37 \pm 1.10^{\mathrm{d}}$ & $34.36 \pm 1.48^{\mathrm{d}}$ & $41.69 \pm 1.57^{\mathrm{e}}$ & $57.46 \pm 2.96^{\mathrm{e}}$ & $72.58 \pm 3.43^{\mathrm{de}}$ \\
PCPR2 & $3969.37 \pm 50.04^{\mathrm{b}}$ & $3409.03 \pm 208.75^{\mathrm{b}}$ & $2748.95 \pm 213.30^{\mathrm{a}}$ & $1941.41 \pm 86.22^{\mathrm{a}}$ & $1684.13 \pm 42.96^{\mathrm{a}}$ & $1231.55 \pm 96.63^{\mathrm{a}}$ \\
\hline
\end{tabular}

SP, superphosphate with; PR1, phosphate rock of Yicheng City; PR2, phosphate rock of Hunan Province; UFPR1 and UFPR2, ultra-fine phosphate rock; PCPR1 and PCPR2, physiochemical pro-release phosphate rock; ${ }^{\text {a, b, c, d, e }} p=0.05$. 
Table 5. Comparison of phosphorus forms between PRs and UFPRs, PCPRs $\left(\mathrm{P}_{2} \mathrm{O}_{5}\right)$

\begin{tabular}{ccc}
\hline Phosphoric fertilizer & $\begin{array}{c}\text { Available P } \\
\left(\mathrm{P}_{2} \mathrm{O}_{5}, \mathrm{mg} \mathrm{kg}^{-1}\right)\end{array}$ & $\begin{array}{c}\text { Labile P } \\
\left(\mathrm{P}_{2} \mathrm{O}_{5}, \mathrm{mg} \mathrm{kg}^{-1}\right)\end{array}$ \\
\hline PR1 & $15616.38 \pm 9.68^{\mathrm{f}}$ & $1476.83 \pm 18.15^{\mathrm{f}}$ \\
UFPR1 & $21642.63 \pm 154.85^{\mathrm{e}}$ & $6076.22 \pm 10.06^{\mathrm{e}}$ \\
PCPR1 & $25270.42 \pm 20.89^{\mathrm{d}}$ & $7259.21 \pm 58.90^{\mathrm{d}}$ \\
PR2 & $44677.06 \pm 29.50^{\mathrm{c}}$ & $3904.29 \pm 0.55^{\mathrm{c}}$ \\
UFPR2 & $57498.27 \pm 432.42^{\mathrm{b}}$ & $12323.33 \pm 77.68^{\mathrm{b}}$ \\
PCPR2 & $63336.38 \pm 129.73^{\mathrm{a}}$ & $17583.55 \pm 10.29^{\mathrm{a}}$ \\
\hline
\end{tabular}

a, b, c, d, e, f $p=0.05$.

\subsection{The physical and chemical structure of PCPR}

Two kinds of phosphate rock (PR1 and PR2) were processed by ultrafine grinding and physicochemical pro-release. The infrared spectrum varied significantly, main variations for the number of new peaks and the emergence of certain correlation peak position and intensity of the peak (Figures 1 and Figure 2). Compared with PR1, the characteristic absorption peak $3440 \mathrm{~cm}^{-1}$ associated with the stretching vibration of adsorbed water in PCPR1 significantly enhanced. The characteristic absorption peaks $1094 \mathrm{~cm}^{-1}, 1046 \mathrm{~cm}$ ${ }^{1}, 603 \mathrm{~cm}^{-1}, 576 \mathrm{~cm}^{-1}, 462 \mathrm{~cm}^{-1}$ related with $\mathrm{PO}_{4}^{3-}$ significantly enhanced, with broad peak shape, and the new bending vibration absorption peak $514 \mathrm{~cm}^{-1}$ related with $\mathrm{PO}_{4}^{3-}$ appeared. The characteristic absorption peak $\left(2524 \mathrm{~cm}^{-1}, 1818 \mathrm{~cm}^{-1}, 881 \mathrm{~cm}^{-1}, 798 \mathrm{~cm}^{-1}, 779 \mathrm{~cm}^{-1}, 729\right.$ $\mathrm{cm}^{-1}$ ) intensity related with $\mathrm{HPO}_{4}{ }^{2-}$ were significantly enhanced. The characteristic absorption peak (1439 $\mathrm{cm}^{-1}, 694 \mathrm{~cm}^{-1}$ ) intensity related with $\mathrm{CO}_{3}^{2-}$ and $\mathrm{HCO}_{3}^{-}$ were also significantly enhanced. Among the infrared absorption spectrum of PCPR1, the absorption peak strength for stretching vibration of adsorbed water absorption peaks $\left(3440 \mathrm{~cm}^{-1}\right)$ and $2524 \mathrm{~cm}^{-1}, 1818 \mathrm{~cm}^{-1}$, $798 \mathrm{~cm}^{-1}, 779 \mathrm{~cm}^{-1}, 729 \mathrm{~cm}^{-1}$ related with $\mathrm{HPO}_{4}^{2-}$ were enhanced compared with that in UFPR1 (Figure 1). Compared with PR2, the characteristic absorption peak
$3440 \mathrm{~cm}^{-1}$ associated with the stretching vibration of adsorbed water in PCPR2 significantly enhanced. The characteristic absorption peaks $1096 \mathrm{~cm}^{-1}, 1041 \mathrm{~cm}^{-1}, 605$ $\mathrm{cm}^{-1}, 569 \mathrm{~cm}^{-1}, 470 \mathrm{~cm}^{-1}$ related with $\mathrm{PO}_{4}^{3-}$ significantly enhanced, with broad peak shape, and the new bending vibration absorption peak $528 \mathrm{~cm}^{-1}$ related with $\mathrm{PO}_{4}^{3-}$ appeared. The characteristic absorption peak $\left(798 \mathrm{~cm}^{-1}\right.$, $779 \mathrm{~cm}^{-1}$ ) intensity related with $\mathrm{HPO}_{4}{ }^{2-}$ were significantly enhanced and the new characteristic peaks $\left(881 \mathrm{~cm}^{-1}, 729\right.$ $\mathrm{cm}^{-1}$ ) were appeared. The intensity of characteristic peaks $\left(1611 \mathrm{~cm}^{-1}\right)$ related with $\mathrm{H}_{2} \mathrm{PO}_{4}$ were enhanced slightly. The characteristic absorption peak $\left(1454 \mathrm{~cm}^{-1}, 1430 \mathrm{~cm}^{-1}\right.$, $695 \mathrm{~cm}^{-1}$ ) intensity related with $\mathrm{CO}_{3}{ }^{2-}$ and $\mathrm{HCO}_{3}^{-}$was also significantly enhanced. Among the infrared absorption spectrum of PCPR2, the absorption peak strength for stretching vibration of adsorbed water absorption peaks $\left(3440 \mathrm{~cm}^{-1}\right)$ and $1611 \mathrm{~cm}^{-1}$ related with $\mathrm{H}_{2} \mathrm{PO}_{4}^{-}$were enhanced compared with that in UFPR2 (Figure 2).

Hence, under the action of mechanical forces, PR and activator underwent a chemical reaction, in which the firm Ca-P binding of the apatite was broken, the phosphate ion such as $\mathrm{PO}_{4}^{3-}, \mathrm{HPO}_{4}^{2-}, \mathrm{H}_{2} \mathrm{PO}_{4}^{-}$activity was significantly enhanced, making that phosphate conversed from the state of hard utilization by plants to the active state in PR and the phosphorus effectiveness was significantly enhanced. 

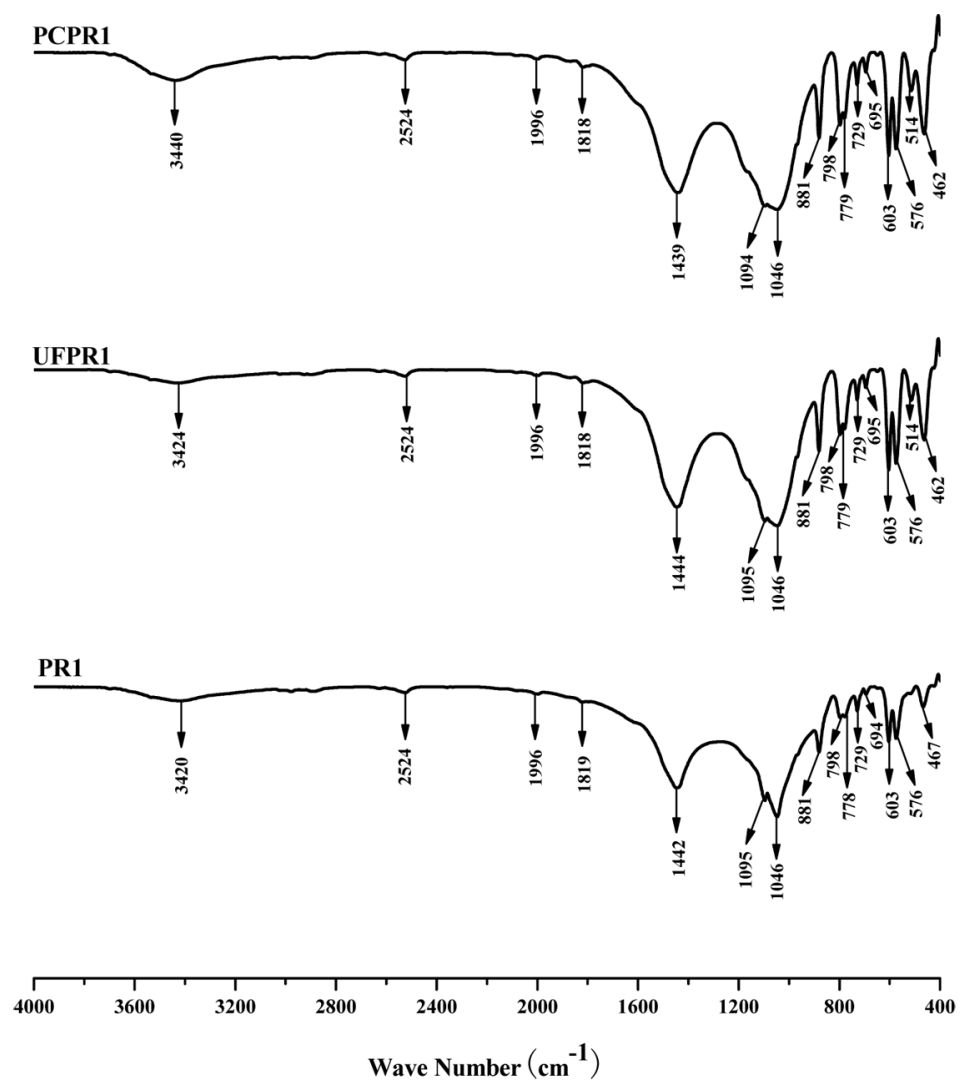

Figure 1. IR of PR1 and UFPR1, PCPR1. PR1, phosphate rock of Yicheng City; UFPR1, ultra-fine phosphate rock; PCPR1, physiochemical pro-release phosphate rock.

The results of the X-diffraction analysis showed that the peak intensity in PR1 and PR2 treated with ultra-fine grinding decreased slightly, but there was no change in phase. Compared with PR1, The $\mathrm{Cl}^{-}, \mathrm{F}^{-}$and dolomite $\mathrm{Fe}^{2+}$ in apatite was replaced after physicochemical pro-release treatment. The $\mathrm{F}^{-}$in apatite was also replaced after physicochemical pro-release treatment of PR2. The main impact of ultra-fine grinding on the structure of phosphate was reducing the degree of crystallization of apatite, without significantly effect on the phase composition of phosphate powder. However, physicochemical pro-release treatment not only can reduce the degree of crystallinity of apatite and the introduce of a hydroxyl group, but also can replace $\mathrm{Cl}^{\text {}}$, $\mathrm{F}^{-}, \mathrm{Fe}^{2+}$ in $\mathrm{PR}$ to change phase composition and further improve the phosphorus effectiveness of PR.(Figure 3)

\subsection{Pot experiments $P C P R$}

Pot experiment showed that after cultivation for 25 days, the corns without treatment phosphate fertilizer (CK) or PRs exhibited obvious deficiency symptoms, growth retardation, small plant and purple leaf. The administration of SP, DAP, UFPRs and PCPRs could 
significantly ease corn leaf deficiency symptoms, promote plant growth, but the edge of the part corn processed with SP, DAP, UFPR1, UFPR2 still appeared purple veins symptoms. Compared with CK treatment, the corn biomass processed with phosphate fertilizer increased significantly, in which the effect of PCPR1, PCPR2 on corn yield was the most significant. The corn biomass were increased 9.21-fold and 10.41-fold compared with CK, respectively. Compared with SP, the corn biomass were increased by $28.67 \%$ and $43.79 \%$, respectively. Compared with DAP, the corn biomass was also increased significantly, with $28.36 \%$ and $43.44 \%$ fold, respectively. (Table 6)
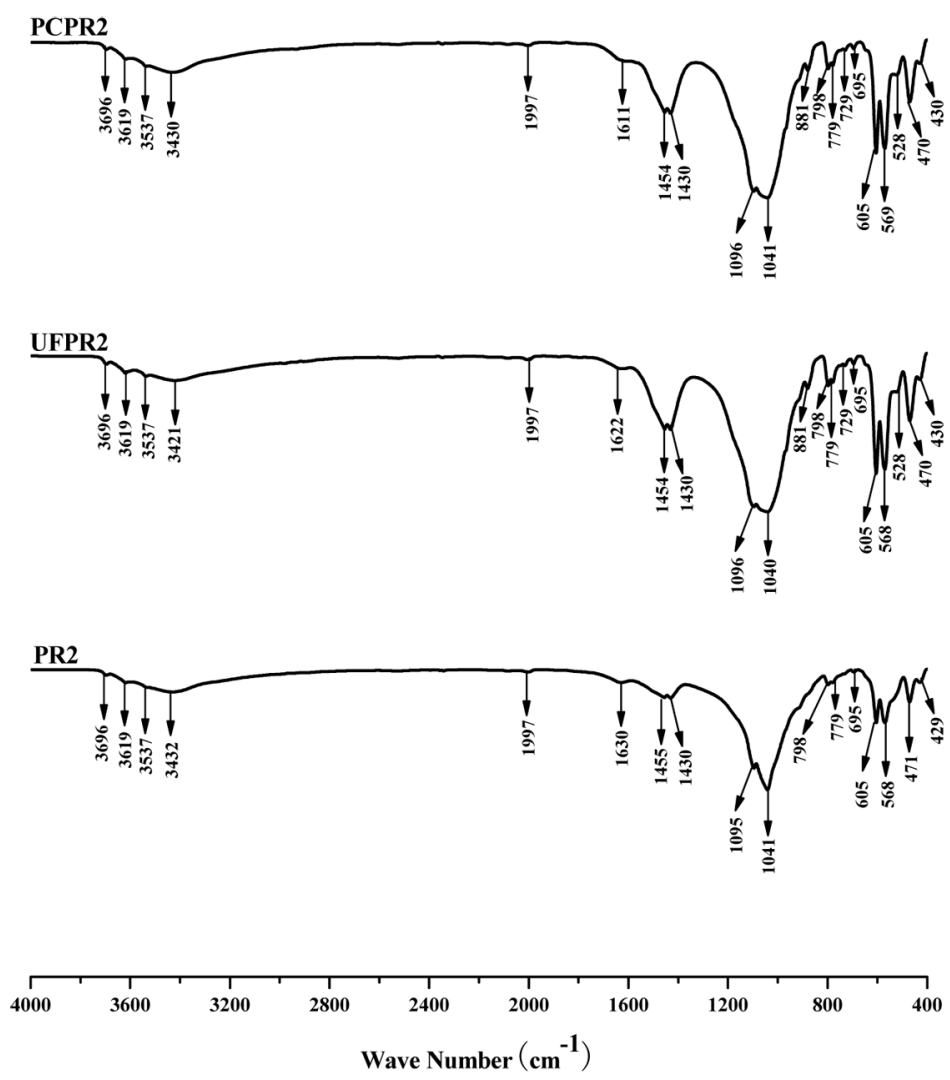

Figure 2. IR of PR2 and UFPR2, PCPR2 PR2, phosphate rock of Hunan Province; UFPR2, ultra-fine phosphate rock; PCPR2, physiochemical pro-release phosphate rock. 

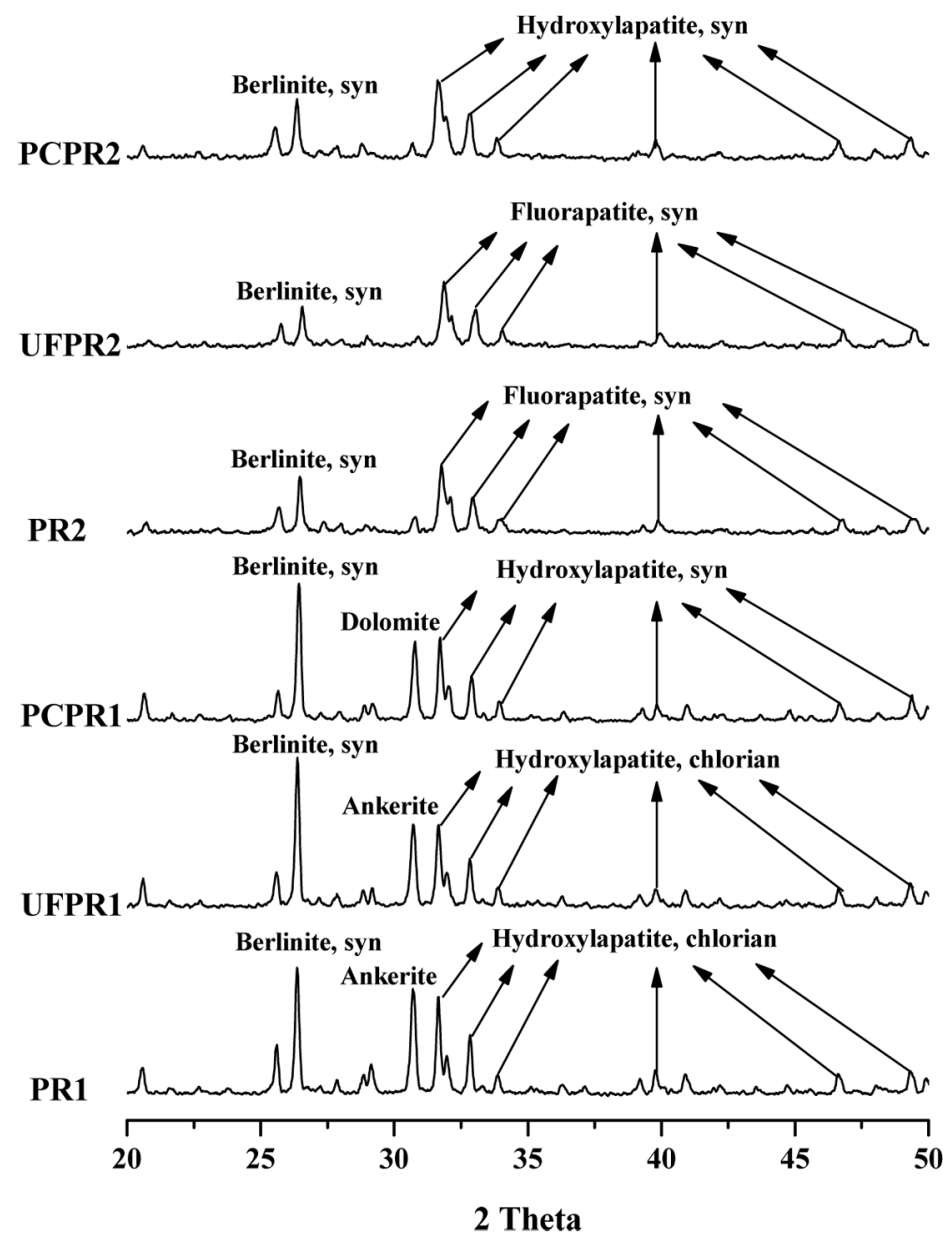

Figure 3. X-ray diffraction pattern of PRs and UFPRs, PCPRs $\mathrm{AlPO}_{4}$, Berlinite, syn; $\mathrm{Ca}\left(\mathrm{Fe}^{2+}, \mathrm{Mg}\right)\left(\mathrm{CO}_{3}\right)_{2}$, Ankerite; $\mathrm{CaMg}\left(\mathrm{CO}_{3}\right)_{2}$, Dolomite; $\mathrm{Ca}_{5}\left(\mathrm{PO}_{4}\right)_{3}(\mathrm{OH}, \mathrm{Cl}, \mathrm{F})$, Hydroxylapatite, chlorian; $\mathrm{Ca}_{5}\left(\mathrm{PO}_{4}\right)_{3} \mathrm{~F}$, Fluorapatite, syn; $\mathrm{Ca}_{5}\left(\mathrm{PO}_{4}\right)_{3}(\mathrm{OH})$, Hydroxylapatite, syn. 
Table 6. The effects of different phosphorus fertilizers on the biomass of corn ( $\left.\mathrm{g} \mathrm{pot}^{-1}\right)$

\begin{tabular}{|c|c|c|c|c|c|c|}
\hline \multirow[t]{2}{*}{ Treatment } & \multirow[t]{2}{*}{ Roots } & \multirow[t]{2}{*}{ Stem-leaves } & \multirow{2}{*}{$\begin{array}{c}\text { Total } \\
\text { biomass }\end{array}$} & \multicolumn{3}{|c|}{ Product increase (\%) } \\
\hline & & & & $\mathrm{CK}$ & SP & DAP \\
\hline CK & $0.41 \pm 0.08^{\mathrm{d}}$ & $2.28 \pm 0.13^{\mathrm{g}}$ & $2.69 \pm 0.07^{\mathrm{g}}$ & --- & --- & --- \\
\hline SP & $2.63 \pm 0.29^{c}$ & $18.72 \pm 1.69^{\mathrm{d}}$ & $21.35 \pm 1.43^{\mathrm{d}}$ & 693.62 & --- & --- \\
\hline DAP & $3.31 \pm 0.49^{\mathrm{b}}$ & $18.09 \pm 0.22^{\mathrm{d}}$ & $21.40 \pm 0.34^{\mathrm{d}}$ & 695.66 & --- & --- \\
\hline PR1 & $0.41 \pm 0.09^{\mathrm{d}}$ & $2.29 \pm 0.20^{\mathrm{g}}$ & $2.70 \pm 0.16^{\mathrm{g}}$ & 0.37 & --- & --- \\
\hline UFPR1 & $2.23 \pm 0.31^{\mathrm{c}}$ & $12.51 \pm 0.60^{\mathrm{e}}$ & $14.74 \pm 0.42^{\mathrm{e}}$ & 447.96 & --- & --- \\
\hline PCPR 1 & $4.27 \pm 0.24^{\mathrm{a}}$ & $23.20 \pm 0.82^{\mathrm{b}}$ & $27.47 \pm 0.60^{\mathrm{b}}$ & 921.19 & 28.67 & 28.36 \\
\hline PR2 & $0.64 \pm 0.08^{\mathrm{d}}$ & $4.23 \pm 0.16^{\mathrm{f}}$ & $4.87 \pm 0.11^{\mathrm{f}}$ & 81.16 & --- & --- \\
\hline UFPR2 & $3.26 \pm 0.34^{\mathrm{b}}$ & $21.73 \pm 0.47^{\mathrm{c}}$ & $24.98 \pm 0.37^{\mathrm{c}}$ & 818.69 & 17.01 & 16.74 \\
\hline PCPR2 & $4.25 \pm 0.36^{\mathrm{a}}$ & $26.45 \pm 0.27^{\mathrm{a}}$ & $30.70 \pm 0.12^{\mathrm{a}}$ & 1041.14 & 43.79 & 43.44 \\
\hline
\end{tabular}

The total phosphorus content and $\mathrm{P}$ uptake content of the plants body can directly reflect the utilization of phosphorus fertilizer (Gourley et al., 1993). Each phosphate treatment could significantly promote corn on phosphorus absorption, improve plant phosphorus content and uptake (Table 7). Plants stems and roots treated with PR1, PR2 were with higher phosphorus content, which was mainly related to their small biomass. The corn stem and root treated with PCPRs were significantly improved in phosphorus content compared with the corresponding UFPRs. Compared with UFPR1, the phosphorus content of corn stem treated with PCPR1 increased by $16.87 \%$, root phosphorus content increased by $34.71 \%$. The phosphorus content of corn stem treated with PCPR2 also increased by $26.37 \%$, root phosphorus content increased by $15.77 \%$, as compared with the UFPR2 . Compared with SP and DAP, the phosphorus content of corn stem and roots treated with PCPR2 were significantly increased by $22.58 \%$ and $10.17 \%$, respectively, root phosphorus content increased by $6.91 \%$ and $33.87 \%$, respectively.
The total P uptake in plants treated with PCPR2 was the highest, and that of the PCPR1 was the second. The total P uptake of PCPR2 and PCPR1 were 21.41 times and 14.07 times of that in CK.

The utilization for SP, DAP and PR were low, the utilization of phosphorus was significantly improved after PR processed by ultra-fine grinding, in which the phosphorus utilization for PCPR1, PCPR2 were up to $58.69 \%$ and $35.68 \%$, respectively. The failure and loss of water-soluble phosphate in the red soil with high content of phosphorus fixation factor such as iron, aluminum and so on, was the main reason for low utilization of phosphate fertilizer. Although water-soluble phosphorus content and available phosphorus content in the PCPRs was not as SP and DAP, persistent dynamic characteristics of release phosphorous not only could meet the continuous phosphorus absorption, but also could reduce the phosphorus loss and soil fixation, thus obtained a high phosphorus utilization, which was not only conducive to crop growth, but also can reduce phosphorus inputs and phosphorus loss harmful to the environment. 
Table 7. Phosphorus use efficiency of the corn crops different in fertilization treatment

\begin{tabular}{|c|c|c|c|c|c|}
\hline Treatment & $\begin{array}{l}\mathrm{P} \text { content of } \\
\text { stem-leave } \\
\left(\mathrm{P}_{2} \mathrm{O}_{5} \mathrm{~g} \mathrm{~kg}^{-1}\right)\end{array}$ & $\begin{array}{c}\mathrm{P} \text { content of } \\
\text { root } \\
\left(\mathrm{P}_{2} \mathrm{O}_{5} \mathrm{~g} \mathrm{~kg}^{-1}\right)\end{array}$ & $\begin{array}{l}\mathrm{P} \text { uptakeof } \\
\text { corn } \\
\left(\mathrm{P}_{2} \mathrm{O}_{5} \mathrm{mg} \mathrm{pot}^{-}\right. \\
\left.{ }^{1}\right)\end{array}$ & $\begin{array}{c}\text { soil Olsen- } \\
\text { P } \\
\mathrm{mg} \mathrm{kg}^{-1}\end{array}$ & $\begin{array}{c}\text { P use } \\
\text { efficiency } \\
(\%)\end{array}$ \\
\hline CK & $1.31 \pm 0.03^{\mathrm{g}}$ & $0.79 \pm 0.04^{\mathrm{g}}$ & $3.31 \pm 0.12^{\mathrm{g}}$ & $2.49 \pm 0.36^{\mathrm{g}}$ & --- \\
\hline SP & $2.04 \pm 0.15^{\mathrm{d}}$ & $1.08 \pm 0.01^{\mathrm{c}}$ & $40.96 \pm 3.15^{\mathrm{d}}$ & $35.75 \pm 1.05^{\mathrm{a}}$ & 10.24 \\
\hline DAP & $2.27 \pm 0.04^{\mathrm{c}}$ & $0.86 \pm 0.00^{f}$ & $43.84 \pm 0.29^{c}$ & $27.79 \pm 0.33^{b}$ & 10.96 \\
\hline PR1 & $1.48 \pm 0.03^{f}$ & $1.12 \pm 0.00^{\mathrm{b}}$ & $3.85 \pm 0.25^{\mathrm{g}}$ & $2.20 \pm 0.15^{\mathrm{g}}$ & 7.47 \\
\hline UFPR1 & $1.58 \pm 0.08^{\mathrm{f}}$ & $0.68 \pm 0.01^{\mathrm{h}}$ & $21.22 \pm 0.80^{\mathrm{e}}$ & $4.67 \pm 0.17^{\mathrm{f}}$ & 29.71 \\
\hline PCPR 1 & $1.84 \pm 0.06^{\mathrm{e}}$ & $0.91 \pm 0.01^{\mathrm{e}}$ & $46.60 \pm 1.31^{\mathrm{b}}$ & $9.83 \pm 0.45^{\mathrm{e}}$ & 58.69 \\
\hline PR2 & $2.86 \pm 0.08^{\mathrm{a}}$ & $1.45 \pm 0.01^{\mathrm{a}}$ & $13.02 \pm 0.37^{\mathrm{f}}$ & $10.57 \pm 0.22^{\mathrm{e}}$ & 8.86 \\
\hline UFPR2 & $1.98 \pm 0.08 \mathrm{~d}^{\mathrm{e}}$ & $0.99 \pm 0.00^{\mathrm{d}}$ & $46.16 \pm 0.77^{\mathrm{b}}$ & $15.87 \pm 0.10^{\mathrm{d}}$ & 24.33 \\
\hline PCPR2 & $2.50 \pm 0.15^{\mathrm{b}}$ & $1.15 \pm 0.02^{\mathrm{b}}$ & $70.92 \pm 0.29^{\mathrm{a}}$ & $18.56 \pm 0.08^{\mathrm{c}}$ & 35.68 \\
\hline
\end{tabular}

a, b, c, d, e, f, g $p=0.05$

Compared with the corresponding ordinary rock phosphate (PR1, PR2), PCPR1 and PCPR2 also significantly increased soil phosphorus content, the soil phosphorus content were increased by 2.95 times and 6.45 times than those with $\mathrm{CK}$ treatment. The correlation analysis showed that there was a significant correlation coefficient $r=0.86(p<0.05)$ between active phosphorus content measured with $1 \mathrm{~mol} / \mathrm{L}$ of acetic acid - sodium acetate $(\mathrm{pH}=4.7)$ and corn biomass, which reflected biological fertilizer better compared with available phosphorus extracted with a $2 \%$ citric acid solution, provided a new measurement tool of rapid evaluation. (Figure 4)

\section{Discussion}

4.1. Mechanism and inspiration of phosphorus availability for $P C P R$

Phosphate rock structure is closely related to its effectiveness. The bonding situation of water-soluble phosphate $\left(\mathrm{H}_{2} \mathrm{PO}_{4}^{2-}\right)$ and weak acid soluble phosphate $\left(\mathrm{HPO}_{4}^{2-}\right)$ in $\mathrm{PR}$ analyzed with infrared spectroscopy and X-diffraction, and the degree of crystallization of apatite could measure direct effect, where the higher $\mathrm{H}_{2} \mathrm{PO}^{4-}$ and $\mathrm{HPO}_{4}^{2-}$ content was, the lower the degree of crystallization of apatite was, the higher phosphorus activity in PR and more easily crop absorbed and used (Cevik et al., 2010). There was a high degree of crystal in PR and low in water-soluble phosphorus and available phosphorus. The PR crystallinity through ultra-fine grinding and the available phosphorus was significantly increased. However, an increase in surface energy of particles significantly enhanced adsorption capacity of phosphorus, limited its water-soluble phosphorus release. Physicochemical treatment not only can significantly reduce the degree of crystallinity of PR, but also can further increase the particle fineness and specific surface area, improve phosphate ions chemically activity such as $\mathrm{PO} 43-, \mathrm{HPO}_{4}^{2-}, \mathrm{H}_{2} \mathrm{PO}^{4-}$ and so on. Meanwhile, high surface activity and ion complexing ability of activators not only reduced phosphate powder particle surfaces promoting desorption of phosphorus, but also further promoted the release of phosphorus with replacement of $\mathrm{Cl}^{-}, \mathrm{F}^{-}$and $\mathrm{Fe}^{2+}$ in apatite. 

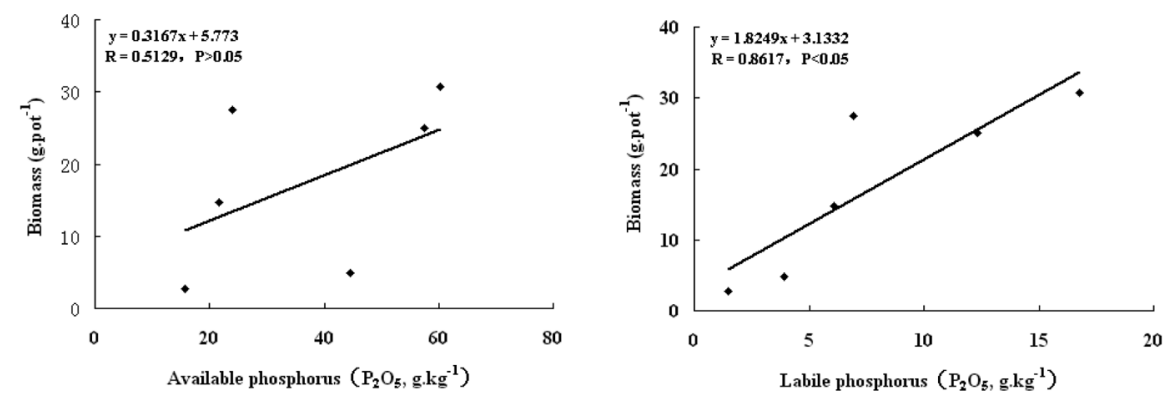

Figure 4. Relation between the available phosphorus, labile phosphorus and pot biomass

The phosphate accumulation of six consecutive extraction soluble phosphorus in PCPR was more than 24 times than ordinary PR, was increased by more than 16 times compared with the same conditions obtained UFPR, with moderate release rate of water-soluble phosphorus and sustainable water-soluble phosphorus release strength at 1000-3000 $\left(\mathrm{P}_{2} \mathrm{O}_{5}\right) \mathrm{mg} \cdot \mathrm{kg}^{-1}$. As the water-soluble phosphorus was the direct phosphorus form plants used, maintaining adequate supply of water soluble phosphorus was basis to improve crop yield, but excessive fertilization could make that water-soluble phosphorus was likely to be fixed in soil or loss with water if not promptly absorbed by crops (Bochove et al., 2007). Hence, the utilization of ordinary water-soluble fertilizer (such as SP, DAP) was low and the PCPR not only can meet crop continuous absorption, but also can reduce the loss of phosphorus and soil fixation, which possessed a high phosphorus utilization.

The PCPR was significantly superior to conventional fertilizer, further indicating that phosphate fertilizer was not only relevant with total phosphorus, but also with water-soluble phosphorus release rate, a key factor affecting phosphate fertilizer. Recently, the determination of the effectiveness of phosphate were measured using one extraction, which can only reflect total supply phosphorus from the available phosphorus content, not from water-soluble phosphorus release strength and durability to reflect phosphorus supply speed. In this study, the combination of measurement of active phosphorus using acetic acid-sodium acetate extraction and water-soluble phosphorus extracted with continuous water extraction and investigation phosphorus supply capacity from the supply volume and speed were beneficial to make a proper evaluation of bio-fertilizer, had important theoretical and practical significance of further research for improving the effectiveness.

\subsection{Prospect and significance of technology applications for PCPR}

There were increasingly acute contradictions between shortage of bonanza phosphorus resources and fertilizer demands, causing a tremendous impact and threats to China's agricultural production and food security (Liao et al., 2011). With high energy consumption and heavy pollution, traditional production of phosphate fertilizer industry technology system was difficult to utilize a lot of LGPR resources effectively. Moreover, phosphorus utilization for the phosphate fertilizer products was low, easy loss with the water causing water pollution, which has been unable to meet the economic and social development needs. How to obtain an efficient use of technology in the traditional framework of phosphate fertilizer production technology has become an important and urgent task. 
Physicochemical pro-release technology can be directly used in the treatment of LGPR resources to develop efficient fertilizer, alleviating the current severe crisis of phosphorus resources and environmental pressures, ensuring our food security and maintaining sustainable development of agriculture, with great strategic significance. In the traditional method of acid phosphate and thermal phosphate-based fertilizer production technology system, most of the phosphate ore must be enriched in order to meet the high concentration of phosphate fertilizer production requirements. In China, the vast majority of phosphate rock was low-grade. On the one hand, it would lose a considerable amount of phosphorus due to difficult processing and high cost beneficiation. Moreover, the lower the phosphate rock grade was, the higher the grade of concentrated phosphate rock was and the greater the loss of phosphorus was. On the other hand, a large number of beneficiation tailings if not properly treated, will not only cause serious environmental pollution, but also contain waste large amounts of tailings phosphorus, calcium, magnesium, iron, manganese, potassium, silicon and other nutrients. Physicochemical pro-release technology eliminating beneficiation can directly utilize LGPR to product fertilizer, not only can significantly save processing costs, effectively avoid environmental pollution and phosphorus losses caused by ore dressing, but also can take full advantage of phosphorus, calcium , magnesium and other nutrients in the LGPR, improve utilization of phosphorus resource, greatly extend mine life phosphate ore.

With the advantages of high efficiency and energy saving, physicochemical pro-release technology played an important role in low-carbon for phosphate fertilizer companies and improving the competitiveness of phosphate fertilizer products. Compared with the traditional acid and the thermal phosphate production technology, physicochemical pro-release technology, whose process was simple and without beneficiation, can save $10 \% \sim 40 \%$ cost and significantly improve the phosphorus effectiveness of LGPR and agricultural value. With a high phosphorus fertilizer utilization and significant fertilizer efficiency, PCPR was better than UFPR, SP and DAP and other conventional fertilizer, not only can reduce phosphorus inputs and save phosphate ore, but also can reduce caused environmental hazards by phosphorus losses.

In addition, with strong mineral surface modification capability, the physicochemical pro-release treatment can effectively utilize lignin, monosodium glutamate wastewater, furfural residue, $\gamma$-polyglutamate and other organic wastes, provide a new way for utilization of industrial and agricultural wastes resources and development of mineral fertilizer sources such as silicon, potassium, magnesium and so on, with broad application prospects.

\section{Conclusions}

Physicochemical pro-release technology can significantly improve the effectiveness of phosphorus availability and agricultural value in low-grade phosphate rock (LGPR). Compared with phosphate rock (PR), phosphorus content in physicochemical pro-release phosphate rock (PCPR) increased by $40 \%$, active phosphorus increased by $350 \%$ times and the 6 consecutive extraction soluble phosphorus accumulation increased by $2400 \%$ with a steady supply of phosphorus characteristics. Fertilizer efficiency and phosphorus utilization were superior to superphosphate (SP) and diammonium phosphate (DAP).

PCPR exhibited good characteristics of release performance and fertilizer efficiency, because physicochemical pro-release treatment significantly reduced crystallization of $\mathrm{PR}$, increased the particle fineness and specific surface area, improved chemical activity of $\mathrm{PO}_{4}^{3-}, \mathrm{HPO}_{4}^{2-}, \mathrm{H}_{2} \mathrm{PO}^{4-}$ and other phosphate ions. Physiochemical pro-release technology for LGPR could save resources and energy, was a major issue in agricultural production to build a conservation-oriented society. PCPR with lignin and PR is a successful attempt to develop LGPR and new 
uses for industrial waste. In the future, researches in this area were of great importance to ease the crisis and develop new phosphorus fertilizer products.

\section{Acknowledgements}

This work was supported by the National Natural Science Foundation of China (41071162) and Agricultural Science and Technology Brainstorm Project of Guangzhou(2010B020311007).

\section{References}

Aria, M.M., Lakzian, A., Haghnia, G.H., Berenji, A.R., Besharati, H., Fotovat, A. 2010. Effect of Thiobacillus, sulfur, and vermicompost on the water-soluble phosphorus of hard rock phosphate. Bioresource Technology. 101(2), 551-554.

Biswas, D.R., Narayanasamy, G. 2006. Rock phosphate enriched compost: An approach to improvelowgrade Indian rock phosphate. Bioresource Technology. 97, 2243-2251.

Bochove, E., Thériault, G., Dechmi, F., Leclerc, M. L., Goussard, N. 2007. Indicator of risk of water contamination by phosphorus: Temporal trends for the province of Quebec from 1981 to 2001. Canadian Journal of Soil Science. 87(2), 121128.

Cordell, D., Rosemarin, A., Schroder, J.J., Smit, A. L. 2011. Towards global phosphorus security: A systems framework for phosphorus recovery and reuse options. Chemosphere. 84, 747-758.

Chien, S.H., Prochnow, L.I., Tu, S., Snyder, C.S. 2011. Agronomic and environmental aspects of phosphate fertilizers varying in source and solubility: an update review. Nutrient Cycling in Agro-ecosystems, 89(2), 229-255.
Cevik, U., Baltas, H., Tabak, A., Damla, N. 2010. Radiological and chemical assessment of phosphate rocks in some countries. Journal of Hazardous Materials. 182, 531-535.

Dawson, C.J., Hilton, J. 2011. Fertiliser availability in a resource-limited world: Production and recycling of nitrogen and phosphorus. Food Policy. 36, 1422.

Gourley, C.I.P., Allan, A.L., Russelle, M.P. 1993. Defining phosphorus efficiency in plants. Plant and Soil. 155/156, 289-292.

He, Z.L., Baligar, V. C., Martens, D.C., Ritchey, K.D., Elrashidi, M. 1999. Effect of byproduct, nitrogen fertilizer, and zeolite on phosphate rock dissolution and extractable phosphorus in acid soil. Plant and Soil. 208, 199-207.

Lu, R.K. 2000. Soil Agricultural Chemistry Analysis. Science and Technology of China Agriculture Press, Beijing, 1-336.

Lu, R.K. 2004. Phosphorus resource of China and phosphate fertilizer production and consumption I. $\mathrm{P}$ resources and $\mathrm{P}$ fertilizers production of China. Soils, 36(1), 1-4.

Liao, Z.W., Mao, X.Y., Liu, K.X. 2011. Pondering over nutrient availability concept and Initiating a new technique of promoted release. Scientia Agricultura Sinica,.44(18), 3918.

Minjigmaa, A., Temuujin, J., Khasbaatar, D., OyunErdene, G., Amgalan, J., MacKenzie, K. J.D. 2007. Influence of mechanical distortion on the solubility of fluorapatite. Minerals Engineering. 20, 194-196.

Osivand, M., Azizi, P., Kavoosi, M., Davatgar, N., Razavipour, T. 2009. Increasing phosphorus availability from rock phosphate using organic matter in rice (Oryza sativa L). Philippine Agricultural Scientist. 92(3), 301-307. 
Pickering, H.W., Menzies, N.W., Hunter, M.N. 2002. Zeolite/rock phosphate-a novel slow release phosphorus fertiliser for potted plant production. Scientia Horticulturae. (94), 333-343.

Schroder, J.J., Smit, A.L., Cordell, D., Rosemarin, A. 2011. Improved phosphorus use efficiency in agriculture: A key requirement for its sustainable use. Chemosphere. $84,822-831$.

Sukhov, B.G., Enkhtuyaa, D., Amgalan, Zh., Vakul'skaya, T.I., Novikova, L.N., Bazarova, Zh. G., Bazarov, B.G. 2007. Effect of mechanical activation on structural-chemical properties of phosphorites. Russian Journal of Applied Chemistry. 80, 6, 853-859.

Taheri, N., Sharif-Abad, H.H., Yousefi, K., RohollaMousavi, S. 2012. Effect of compost and animal manure with phosphorus and zinc fertilizer on yield of seed potatoes. Journal of Soil Science and Plant Nutrition. 12 (4), 705-714.
Van Vuuren, D.P., Bouwman, A.F., Beusen, A.H. W. 2010. Phosporus demand for the 1970-2100 period: A scenario analysis of resourse depletion. Global Environmental Change. 20(3), 428-439.

Walker, R.L., Edwards, A.C., Maskell, P., Watson, C. A., Rees, R.M., Knox, O.G.G., Stockdale, E.A. 2012. The effect of co-composted cabbage and ground phosphate rock on the early growth and $\mathrm{P}$ uptake of oilseed rape and perennial ryegrass. Journal of Soil Science and Plant Nutrition. 175 (4), 595-603.

Zheng, D.Z. 1989. Accurate determination of active phosphorus. Rock and Mineral Rock and Mineral Analysis. 8(1), 35-39. 